\title{
Abstracts of the meeting of the Clinical Genetics Society held on 7 and 8 April 1988 at the University of Oxford
}

\author{
The natural history of the Gorlin (naevoid basal cell \\ carcinoma) syndrome \\ P FARNDON \\ Clinical Genetics Unit, Birmingham Maternity Hospital.
}

The NBCCS (Gorlin syndrome) is an autosomal dominant disorder of high penetrance but variable expressivity, characterised by multiple basal cell carcinomata, jaw keratocysts, skeletal anomalies, and other developmental malformations including palmar pits and calcification of the falx cerebri. There is also an increased incidence of non-cutaneous tumours. The condition has a very variable expression especially between families. Some families have a distinct phenotype with (among other features) a large head with marked bossing. Children in these families tend to be extensively investigated for this and their initial developmental delay. Regular screening for jaw cysts and basal cell carcinomata should be offered to family members shown to have the syndrome after careful clinical examination and radiological studies. The phenotypic spectrum and the natural history are described from a clinical and genetic study of over 75 patients.

Greig cephalopolysyndactyly (GCPS): a clinical survey, identification of a mouse model, and molecular genetic studies

S M HUSON*, L BRUETON* ${ }^{*}$, R WILlIAMSON†, AND R M WINTER*

*Division of IMD, Clinical Research Centre, Harrow; and tDepartment of Biochemistry, St Mary's Hospital Medical School, London.

GCPS is a complex form of human polysyndactyly with autosomal dominant inheritance. Seven families have been ascertained and 36 affected subjects examined to assess the clinical variability of the condition. The clinical features of GCPS were (in the hands): broad thumbs (26/36), postminimi (25/36), and syndactyly (21/36) and (in the feet): preaxial polydactyly $(26 / 36)$, postaxial polydactyly $(1 / 36)$, and syndactyly (36/36). Affected subjects had very varying degrees of facial dysmorphism (macrocephaly, prominent nasal bridge, high forehead). GCPS has been provisionally assigned to $7 \mathrm{p} 13$ based on two families in which balanced reciprocal translocations segregate with the disease $(\mathrm{t}(3 ; 7)(\mathrm{p} 21 \cdot 1 ; \mathrm{p} 13)$, Tommerup and Neilson, 1983; $\mathrm{t}(6 ; 7)(\mathrm{q} 27 ; \mathrm{p} 13)$, Pelz et al, 1986). Chromosomal analysis from one affected subject per family was normal in the present study. Samples for DNA analysis from 61 family members have been obtained and preliminary linkage studies using 7p DNA markers support localisation of GCPS to 7p13. A search for a mouse model for GCPS has revealed a very similar mutant, xt-extra toes. Further- more, this mutant maps to mouse chromosome 13 in a region homologous to $7 p$ in the human.

Familial multi-infarct dementia associated with cerebral vasculopathy

D R GOUDIE*, D DOYLE $\dagger$, W F DURWARD $\ddagger$, G WARWICK $\ddagger$, J RUNCIE\$, H BELFORD\|, AND J M CONNOR*

*Duncan Guthrie Institute of Medical Genetics, Yorkhill, Glasgow; tInstitute of Neurological Sciences, Southern General Hospital, Glasgow; $¥$ The Royal Infirmary, Glasgow; \$Ruchill Hospital, Glasgow; and \|Gartloch Hospital, Glasgow.

We present a large family in which five men and five women in three generations were affected by a chronic progressive neuropsychiatric disorder. The pattern of inheritance suggests that the condition is inherited as an autosomal dominant trait, although $\mathrm{X}$ linked inheritance could not be excluded. Symptoms of the disorder, which include dementia with pyramidal and bulbar abnormalis ties, began between the third and sixth decades. Conō fusional episodes associated with more marked focaF neurological signs and increasing residual neurological deficit characterised the progression of the illness. One subject is still alive (with severe disability) 14 years after the onset of symptoms. Detailed neuropathological studies in one patient showed multiple old and recent cerebral and brain stem infarctions, which were associated with occlusive disease of small intracerebral blood vessels. The vascular changes were restricted to the central nervous system. CT and MRI scan abnormalities and necropsy findings in five other subjects were consistent with the diagnosis of multi-infarct dementia. This disorder appears similar, if not identical, to that described in three other families reported, but distinct from cerebral vasculopathies listed in the current edition of Mendelian inheritance in man.

An XX male and two t (X;Y) females with linear skin defects and congenital microphthalmia: a new syndrome at $\mathrm{Xp22} \cdot 3$ L I AL-GAZALI*, R F MUELleR*, A CAINE $\dagger, \mathrm{N}$ DENNIS $\ddagger$, A

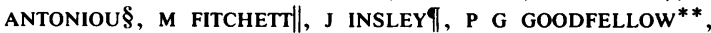
AND M HULTÉN††

${ }^{*}$ Dept of Genetic Counselling, Leeds General Infirmary; †Dept of Cytogenetics, St James’s Hospital, Leeds; $\neq$ Dept of Child Health, Southampton General Hospital; \$Royal Hampshire County Hospital, Winchester; \|Wessex Regional Cytogenetics Unit, Salisbury; \Queen Elizabeth Hospital, Birmingham; **ICRF, Lincoln's Inn Fields, London; and ††Dept of Cytogenetics, East Birmingham Hospital.

Demonstration of cytogenetic abnormalities in children 
with syndromes of single gene or unknown aetiology can lead to the location and eventual isolation of the DNA sequences involved. We describe a $46, \mathrm{XX}$ male and two females with de novo Xp;Yq translocations who presented at birth with irregular linear areas of erythematous skin hypoplasia involving the head and neck, along with eye findings which included microphthalmia, corneal opacities, and orbital cysts. The features in these children are similar to, but distinct from, those seen in females with the Goltz syndrome. Cytogenetic analysis has revealed the $X$ chromosome breakpoint in both $\mathrm{Xp} ; \mathrm{Yq}$ translocation females to be at Xp22-3. DNA analysis in the affected male shows the presence of Yp material thought to have been exchanged to the tip of the short arm of one of his $\mathrm{X}$ chromosomes. We suggest that this syndrome results from a deletion or disruption of DNA sequences in the region of $\mathrm{Xp} 22 \cdot 3$.

Familiarity, recessivity, and germline mosaicism J H EDWARDS

Genetics Laboratory, Department of Biochemistry, University of Oxford.

In man, evidence of recessivity is usually based on a high sib risk, absence of parent-child transmission, and, in rare conditions, excessive consanguinity. Discrimination from what is sometimes called multifactorial disease and from the inevitable associated environmental effects is usually based on a lower recurrence risk, an increased recurrence risk after a second affected child, and no increased consanguinity. A further cause of familial disorder which has received little attention is germline mosaicism for a mutation expressed as a dominant. If, for example, an embryonic mutation had resulted in half the precursors of the germ cells carrying a dominant mutation, then the recurrence risk, that is the proportion of affected gametic nuclei after meiosis, would be a quarter, and if severity precluded reproduction, the disorder would tend to be classified as a recessive. While germline mosaicism will rarely be expressed with such a high recurrence risk, the estimation of recurrence risk in rare disorders is difficult owing to ascertainment, as it occurs in practice, making the assumptions implicit in allowing for it unrealistic. Some numerical consequences of familial disease due to recessivity, generalised predispositions, and germinal mosaicism will be considered.

Investigation of haplotype patterns in carriers of the PKU allele in Welsh gypsy families using the phenylalanine hydroxylase cDNA probe

L A TYFIELD, A L MEREDITH, AND P S HARPER

Institute of Medical Genetics, University of Wales College of Medicine, Cardiff.

Six restriction enzymes highlight eight polymorphisms at the phenylalanine hydroxylase (PAH) locus. Using the cDNA probe for the PAH locus (kindly donated by Dr S Woo, Houston) and these six enzymes we have defined the haplotype pattern of the PKU allele in the extensive and highly consanguineous Welsh gypsy population. More than
30 family members including two children (not sibs) who biochemically have classical PKU were studied. The two children are homozygous for the same haplotype pattern and we were able to track the PKU allele through four generations in one branch of the family. The very high degree of consanguinity of this population is enabling us to examine whether the two affected children have inherited the two PKU alleles from one common ancestor. The haplotype pattern associated with the mutant or classical $\mathrm{PKU}$ allele in this population is the same as one which is reported to be associated with a less severe phenotype in the northern European population.

Alphafetoprotein levels in pregnancies with trisomy 21, 18, and 13

J A CROSSLEY*, M ZEITUNE*, D A AITKEN*, J R W YATES $\dagger$, A COOKE*, G W GRAHAM*, M A FERGUSON-SMITH $\dagger$, AND J M CONNOR*

*Duncan Guthrie Institute of Medical Genetics, Yorkhill, Glasgow: and +Cambridge University Department of Pathology, Cambridge.

Second trimester maternal serum alphafetoprotein (MSAFP) levels were studied retrospectively in 142 pregnancies with autosomal trisomy (114 trisomy 21,19 trisomy 18 , and nine trisomy 13 ) uncomplicated by neural tube or abdominal wall defects. The median value for all affected pregnancies was found to be reduced at 0.72 multiples of the median (MOM) for unaffected pregnancies. Specifically for trisomy 21 , the median was $0.73 \mathrm{MOM}$ and for trisomy 18 and 13 combined, 0.70 MOM. Amniotic fluid AFP levels were analysed in 65 pregnancies affected by autosomal trisomy ( 52 trisomy 21 , nine trisomy 18 , and four trisomy 13). Lower levels of amniotic AFP were found in trisomy 21 pregnancies ( $0.60 \mathrm{MOM}$ of unaffected pregnancies), but the levels in trisomy 18 and 13 pregnancies were not significantly different (0.95 MOM) from unaffected pregnancies. A different mechanism for the reduction of MSAFP may operate in trisomy 21 pregnancies as opposed to trisomy 18 and 13 pregnancies. The reduction in MSAFP levels may be used as a basis of a screening policy for autosomal trisomies.

Mid-trimester fetal malformations studied in Cardiff, 1984 to 1986

K M LAURENCE

Institute of Medical Genetics, Cardiff.

Between 1984 and 1986, 590 fetuses of 15 weeks' gestation or more, including 279 post-termination specimens, have been examined. In nearly all the latter, the expected fetal malformation was confirmed, including 132 neural tube defects and 40 chromosome abnormalities, but also some additional malformations not anticipated from the prenatal diagnostic tests. In 26 cases, no malformation was found, including nine fetuses aborted late for medicosocial reasons, eight aborted for maternal indication, and seven where ultrasound examination suggested serious defect, often hydrocephalus. The 124 spontaneously aborted fresh fetuses and the 187 macerated fetuses included 29 and 28 
respectively with a major malformation, a total of $19 \%$ in the late spontaneous abortions. The importance of a full examination and recording of information on aborted fetuses for the control of the quality of the prenatal diagnostic service, for assessment of prognosis, and for realistic genetic counselling is stressed. This should include a photographic record of dysmorphic features and malformations, where indicated a chromosome examination, and a fetal $x$ ray in addition to the usual naked eye and histological examination. In some cases the need for taking DNA material for future examination should also be kept in mind.

Amniotic fluid vitamin $B_{12}$ and transcobalamins in neural tube defect pregnancies

M J SELLER AND P GARDIKI-KOUIDOU

Paediatric Research Unit, UMDS (Guy's Campus),

London.

Levels of vitamin $B_{12}$, the vitamin $B_{12}$ binding proteins (apotranscobalamin I, II and III), and the unsaturated vitamin $B_{12}$ binding capacity (UBBC) were measured in midtrimester amniotic fluids from normal pregnancies and from those where the fetus had an open neural tube defect (NTD) or an omphalocele, and also where the fetus was normal, but the mother had had a previous NTD child. Vitamin $B_{12}$ levels were lower than normal in the fluids of both types of abnormal fetuses, and also in those of normal fetuses where there had been a previous NTD sib. By contrast, levels of the transcobalamins and UBBC were abnormally high in the NTD and previous NTD fluids. From these findings we wish to propose that part of the genetic predisposition to NTD may be located in a defect connected with vitamin $B_{12}$ production, transport, or metabolism.

Fetal blood sampling in the investigation of chromosome mosaicism in amniotic fluid cell culture

CHRISTINE GOSDEN*, K H NICOLAIDES $\dagger$, AND C H RODECK $\dagger$ ${ }^{*}$ MRC Clinical \& Population Cytogenetics Unit, Edinburgh; and †King's College Hospital, London.

Forty-one pregnancies where mosaicism was found on amniotic fluid culture (AFC) were investigated further by fetal blood and repeat AFC karyotyping. The results from both investigations and the infants were normal in 15 of 16 cases of autosomal trisomy (including trisomies 8, 9, 13, 18 , and 21) and in the eight cases of sex chromosome mosaicism. However, in one case of trisomy 20 mosaicism, the fetal blood karyotype and the infant were normal but the repeat AFC showed mosaicism. The abnormality was confirmed in five of 11 cases of mosaicism for structural chromosomal rearrangements and four of six cases with de novo supernumerary marker mosaicism. These findings show the potential danger of terminating pregnancies because of trisomic mosaicism in AF culture, but the importance of identifying clinical significance of certain chromosome rearrangements which even in mosaic form might lead to severe mental and developmental handicap. They indicate the need for further investigation of amniotic fluid mosaicism by fetal blood sampling and karyotyping.
Predictive testing for Huntington's disease: methods and $\stackrel{\mathbb{P}}{+}$ problems

MICHAEL MORRIS, AUDREY TYLER, LINDA MEREDITH, AND PETER HARPER

Institute of Medical Genetics, University of Wales College of Medicine, Cardiff.

The main characteristics of 100 referrals for predictive tests for Huntington's disease are described. Mean age was $32.8 \mathrm{c}$ years (range 2 to 67 ) and there was a female preponder- $\overrightarrow{0}$ ance of $1 \cdot 6: 1$. Sources of referral were self-referral $(45 \%)$, clinical geneticists $(39 \%)$, and others $(16 \%)$. Thirty-three $\vec{\omega}$ preliminary interviews have been completed and reasons offered for predictive testing have been subjectively rated on a 10 point scale. Over half of these subjects have currently indicated their wish to continue with predictive $N$ testing. An outline of the protocol included discussion of 6 aims, inclusion criteria $(50 \%$ risk, age over 18 years, क potentially informative pedigree), exclusion criteria (signi- $\infty$ ficant risk of suicide, serious psychiatric disorder, sub- 윽 stance misuse), and the main standardised instruments to assess psychiatric (Past History Schedule, Present State $\mathscr{D}$ Examination, General Health Questionnaire), personality $\mathbb{D}$ (Eysenck Personality Questionnaire), and social (Social $\underset{\mathbb{D}}{\vec{C}}$ Maladjustment Interview) variates. Problems associated 3 with informed consent, maintenance of confidentiality, unintentional risk alteration, collection of blood samples, and counselling of affected consultands have been encourg tered.

Preparative pulsed field gel electrophoresis: application to the dystrophin locus

J R HONEYCOMBE, R ANAND, P A WHITTAKER, Y BOYD, AND E M SOUTHERN

Department of Biochemistry, University of Oxford.

Detailed analysis of a large region of a genome is facilitated by generating overlapping clones covering the entire region. These clones are usually obtained by bidirectional 'walking' using either bacteriophage lambda or cosmid cloning vectors, but this is a slow procedure from a single start site. Multiple start sites are an advantage and $\dot{\sigma}$ here we describe a method of generating clones from an 3 extensive region of the Duchenne muscular dystrophy (DMD) locus by preparative pulsed field gel electrophoresis. Twelve clones which map to a $840 \mathrm{~kb} S f i$ fragment surrounding the $5^{\prime}$ end of the DMD gene were 음 isolated. Localisation of these clones to four subregions of $\frac{7}{0}$ the $840 \mathrm{~kb}$ fragment indicates that the clones are distributed throughout the fragment. These clones are now $N$ being used as start sites to isolate groups of contiguous or lambda clones and around $300 \mathrm{~kb}$ of the $840 \mathrm{~kb}$ Sfi N fragment have been cloned.

Magnetic resonance spectroscopy of muscular dystrophies SIMON P FROSTICK, DORIS J TAYLOR, AND GEORGE KRADDA Clinical Magnetic Resonance Unit, John Radcliffe Hospital, Oxford.

Changes were measured in the high and low energy phosphates, as detected by 31-phosphorus magnetic 
resonance spectroscopy. The changes in high energy phosphates indicate an abnormality in ATP production/ utilisation. The changes in low energy phosphates probably indicate alterations in the metabolism of membrane phospholipids. There is a clinical correlation between the degree of involvement of a particular muscle and the detected changes. Different dystrophies show different patterns of involvement.

Translocation mapping by pulsed field electrophoresis T MEITINGER*, $\mathrm{R}$ ANAND $\dagger, \mathrm{Y}$ BOYD*, I W $^{*}$ CRAIG $^{*}, \mathrm{~J}$ H EDWARDS*, M FERGUSON-SMITH $\ddagger$, R H LINDENBAUM§, AND G H VAN OMMEN\|

${ }^{*}$ Genetics Laboratory and + Department of Biochemistry, University of Oxford; $¥$ Department of Pathology, University of Cambridge; §Department of Medical Genetics, Churchill Hospital, Oxford; and ||Department of Human Genetics, University of Leiden.

Eleven breakpoints in females who carry reciprocal $\mathrm{X}$; autosomal translocations with breakpoints in Xp21 have been positioned on a long range restriction map of the DMD region using PFG electrophoresis. Hybridisation of a number of probes from the DMD region with $S f i I$ digested DNA from controls and translocation cell lines, and measurement of altered fragments arising from translocated chromosomes, allowed the breakpoint positions to be determined with various accuracies, ranging from 50 to $200 \mathrm{~kb}$. The two non-DMD cell lines investigated do not show alterations of any of the Sfil fragments known to contain part of the DMD gene. The DMD associated translocation breakpoints are distributed over a region of $2000 \mathrm{~kb}$ covered by the DMD cDNA. No clustering of breakpoints could be observed.

\section{Posters}

Undetectable maternal serum PAPP-A in Cornelia de Lange syndrome

G W GRAHAM, D A AITKEN, AND J M CONNOR

Duncan Guthrie Institute of Medical Genetics, Yorkhill, Glasgow.

Westergaard et al (Prenat Diagn 1983;3:225-32) reported a deficiency of pregnancy associated plasma protein A (PAPP-A) in maternal serum samples obtained between 20 and 35 weeks' gestation from a patient who gave birth to a male infant with Cornelia de Lange (CdL) syndrome. We report here the results of the investigation of maternal serum PAPP-A levels in a 34 year old mother who gave birth to a girl with $\mathrm{CdL}$ syndrome. A blood sample which had been stored at $-20^{\circ} \mathrm{C}$ after routine maternal serum AFP analysis at 17 weeks' gestation was assayed retrospectively for PAPP-A concentration by immunoelectrophoresis along with a control group of 91 serum samples. Between 16 and 20 weeks' gestation the concentration of PAPP-A in maternal serum increases with advancing gestation. Repeated analysis failed to show any PAPP-A in the patient sample. In the absence of any knowledge concerning the basic defect in $\mathrm{CdL}$ syndrome, but with recurrence risks estimated at 2 to $5 \%$, a deficiency of PAPP-A in maternal serum in the second trimester may be a useful marker for prenatal diagnosis in families at risk.
Fetal sexing using the polymerase chain reaction technique A J IVINSON, R G ELLES, A P READ, AND R HARRIS St Mary's Hospital, Manchester.

The polymerase chain reaction (PCR) technique was used to amplify a male specific DNA sequence, using chorionic villus samples (CVS) as the target DNA, in order to give early and fast fetal sexing. Both extracted DNA and disrupted whole CVS tissue were used. Flanking primers of between 20 and 26 base pairs were prepared for a Y chromosome $3.4 \mathrm{~kb}$ repeat sequence and a ubiquitous $A l u$ repeat sequence. PCR amplification reactions were set up for the Y repeat and Alu repeat sequences using $1 \mu \mathrm{g}$ of CVS extracted genomic DNA or a sample of the disrupted villus tissue. Reactions were run for 20 rounds using four units of the heat stable Taq polymerase enzyme added at round one. Amplified DNA was electrophoresed in 3\% 'Nuseive' agarose gels with ethidium bromide and visualised under short wave ultraviolet illumination. The $A l u$ repeat sequence forms an effective control against a failure of the technique. Using this technique a series of 26 previously sexed CV samples were used in a blind study. It was found that fetal sex could be determined from a very small CVS in less than five hours.

The use of transabdominal placental biopsies as a possible alternative to amniocentesis

JOHN WOLSTENHOLME*, DAVID A LITTLE†, A M HOOGWERF*, AND H SHERIDAN*

*Cytogenetics Laboratory, Department of Medical Genetics, Churchill Hospital; and +Department of Obstetrics and Gynaecology, John Radcliffe Hospital, Headington, Oxford.

Rapid karyotyping has been performed on a series of 70 transabdominal placental biopsies taken at more than 16 weeks' gestation. Sampling success has been greater than $95 \%$ and the material obtained has proved suitable for both direct chromosome preparations and long term culture using methods identical to those used for first trimester biopsies. Results obtained from direct preparations were routinely confirmed using either long term cultures or amniotic fluid samples taken at the same time. Five fetuses with chromosomal abnormalities were detected: $46, \mathrm{XX},-14,+\mathrm{t}(14 \mathrm{q} 21 \mathrm{q}) ; 47, \mathrm{XX},+21 ; 47, \mathrm{XX},+21$; $47, \mathrm{XY},+18$; and $45, \mathrm{XO}$. The latter three were detected after suspicious findings during ultrasound scanning and the technique has been found particularly useful in such cases.

Duchenne muscular dystrophy: regional study

A MICIAK, G M COCHRANE, J H EDWARDS, J HOPKINS, A KEEN, R H LINDENBAUM, AND C G NORBURY

University of Oxford.

This region with a population of 2500000 and 33000 births a year now has 206 families on its register; this also includes families referred from outside, mainly to the Nuffield Orthopaedic Clinic. DNA has been extracted from 71 affected boys and from 630 relatives and cell lines established from 36 boys. The files are maintained in 
dBASE III and supplemented by automatic pedigree drawing. A total of 68 affected boys has been screened for deletions using the cDNA probes CF56a and CF56b; $52 \%$ of boys with Duchenne muscular dystrophy and $80 \%$ of boys with Becker muscular dystrophy have a deletion.

\section{Media coverage of Huntington's chorea \\ C PEACOCK AND R HARRIS \\ Department of Medical Genetics, St Mary's Hospital, Manchester.}

On 27 June 1987, BBC television transmitted a programme on the predictive test for those at risk of developing Huntington's chorea. The number and nature of referrals to the Department of Medical Genetics in Manchester in the subsequent three months highlights both the benefits and problems of such media coverage. Six times more referrals (50) were received, resulting in four times more (278) high risk relatives requiring counselling than in any previous year. Five times more (148) were of child bearing age. One third (18) requested predictive or fetal tests. Colleagues referred nine patients to us for confirmation of diagnosis. All required counselling, many having concealed their risk and anxiety for many years. Only 12 new subjects of the 1879 at risk in the North West known to the department were referred, reflecting the value of the genetic register.

\section{Congenital proximal tubular immaturity M CRAWFORD, R A RISDON, AND P MACMAHON Clinical Research Centre, Institute of Child Health, and Charing Cross Hospital, London.}

Following severe oligohydramnios, a mother delivered a female infant with marked Potter's syndrome and complete anuria who died at 27 hours. The fetal kidneys had appeared to be of normal size on ultrasound examination and appeared grossly normal at necropsy. However, histology showed marked immaturity of the tubules, especially the proximal tubules, confirmed by positive immunostaining with epithelial membrane antigen. Identical findings were reported in a brother and sister in December 1986 by Schwarz et al (Hum Pathol 1986;17: 1259). In both their family and the present families the parents were unrelated. Nevertheless, it is proposed that this new nephropathy is inherited in an autosomal recessive manner.

\section{Genetic aspects of psoriatic arthritis}

J S LAWRENCE, L MARTINS, G DRAKE, R CHURCH, K GELSTHORPE, G MORRELL, AND P GRECH

Hallamshire Hospital, Sheffield.

We have examined the first degree relatives and spouses of unselected patients with psoriasis with and without arthritis and have taken $x$ rays of the hands, feet, and sacroiliac joints. A sample of blood was tested for $\mathrm{A}, \mathrm{B}$, and $\mathrm{Cw}$ antigens. The completion rate was $93 \%$ in probands and relatives and $92 \%$ in spouses. Definite psoriasis was found in $17 \%$ of sibs and $14 \%$ of parents and offspring compared with $4.7 \%$ in spouse controls. The data give a reasonable fit for polygenic inheritance with a heritability of $63 \%$. Polyarthritis of rheumatoid type was noted in $10 \%$ of relatives of probands with psoriatic arthritis, compared with $5 \%$ in a population sample $(p=0.0001)$. In relatives of psoriatic probands without arthritis, no excess of arthritis was found. Of the HLA antigens studied, B17, B13, and Cw6 segregated in relatives of psoriatic probands without arthritis. HLA-A1-B17, A19-B13, and B13-Cw6 phenotypes showed an increased frequency in psoriatic families without arthritis. It is concluded that psoriatic arthritis involves genes which are not identical with those concerned in psoriasis.

Detection of a de novo $15 q$ deletion in a child with Angelman's syndrome by cytogenetic analysis and flow cytometry

A COOKE*, J L TOLMIE*, F J GLENCROSS*, E BOYD*, M M CLARKE*, R DAY $\dagger$, J B P STEPHENSON $\dagger$, AND J M CONNOR* ${ }^{*}$ Duncan Guthrie Institute of Medical Genetics; and †Fraser of Allander Assessment Unit, Royal Hospital for Sick Children, Yorkhill, Glasgow.

A proximal 15q deletion, del(15)(q11q13), was detected in a child with Angelman's syndrome by cytogenetic analysis of peripheral lymphocytes. The chromosomes of both parents appeared normal. Flow karotype analysis carried out on lymphoblastoid cell lines derived from the child and her parents confirmed that the deletion had arisen de novo. The estimated size of the deleted segment ranges from $6 \cdot 1$ to $9 \cdot 5 \%$ of chromosome 15 (approximately 6 to 9.3 million base pairs). The parental origin of the deletef chromosome could not be resolved by flow cytometry, but cytogenetic evidence suggested that it was derived from the smaller chromosome 15 homologue in the mother.

Ocular and genetic findings in Angelman's syndrome A J DICKINSON*, A R FIELDER* ${ }^{*}$ D P DUCKETT $\dagger$, AND I D YOUNG $\ddagger$

Departments of Ophthalmology*, Cytogeneticst, and Child Health $\neq$, Leicester Royal Infirmary, Leicester.

Six out of eight children, aged three to 10 years, with a confirmed diagnosis of Angelman's syndrome showed a striking deficiency of choroidal pigment but with normal foveal reflexes. All six had light blue irides with normal iris architecture. One child had brown irides with normal choroidal pigmentation. Four of the eight children had strabismus. All had apparently normal vision. All eight children were isolated cases born to healthy, unrelated parents. All 10 sibs were normal. There was no parental age effect. The presence or absence of chromosome $15 q$ microdeletions did not correlate with ocular findings.

Deletion of $15 q$ in two patients with non-Prader Willi syndrome phenotypes

J JONES AND N C NEVIN

Regional Cytogenetic Laboratory, Department of Medical Genetics, Belfast City Hospital, Belfast.

Deletion of chromosome 15 , involving the bands $15 q 11-$ 13 , is usually associated with the Prader-Willi syndrome. . . . 
However, 17 patients have been reported who do not show the Prader-Willi syndrome but have a deletion of $15 q$ (Schwartz et al, 1985; Greenberg et al, 1987). We report on two additional patients with different phenotypes, neither typical of the Prader-Willi syndrome. Our first patient showed marked developmental delay, microcephaly, and dysmorphic features, his facies characterised by sparse hair, prominent veins, full nasal bridge, prominent, cup shaped ears, anteverted nares, red cheeks, and an overall narrow face. The karyotype showed a deletion of $15 q 12$. Our second patient, a newborn infant, presented with ambiguous genitalia and abnormal facies; characteristics included a small pinched face, a naevus flammeus in the glabella region, small upturned nose, hydrocephalus, and high arched palate. The karyotype (XY) showed a deletion of 15q11. These non-Prader-Willi syndrome phenotypes suggest that a number of different phenotypes may be associated with a deletion on chromosome 15 . The Angelman syndrome is also thought to involve a deletion on $15 q$; our patients, however, are not typical of this syndrome either.

Chromosomal assignment of a glutamic acid transfer RNA (tRNA $^{\text {Glu }}$ ) gene to 1 p36

E BOYD*, A THERIAULT *, J P GODDARD $\dagger$, M KALAITSIDAKI*, D H SPATHAS*, AND J M CONNOR*

${ }^{*}$ Duncan Guthrie Institute of Medical Genetics, Yorkhill, Glasgow; and +Department of Biochemistry, University of Glasgow.

Goddard et al (Nucleic Acids Res 1983;11:2551-62) cloned and characterised a gene for glutamic acid transfer RNA (tRNA ${ }^{\text {(lu }^{\mathrm{u}}}$ ) from a human fetal liver genomic library. By in situ hybridisation using radioactive and biotin labelling, this $2.4 \mathrm{~kb}$ DNA sequence was assigned to human chromosome 1p36. In the biotin experiments a second (statistically significant) site of hybridisation was observed at $1 \mathrm{q} 21.22$ which might represent a pseudogene or related sequence. In fibroblasts from both a gorilla (Gorilla gorilla) and a chimpanzee (Pan troglodytes) using biotin labelling, a single site of significant hybridisation occurred at 1qter. This provides further support for homology of 1 qter in the great apes with 1p36 in man. The secondary site of human hybridisation in the proximal long arm mirrors the map distribution of the U1 small nuclear RNA genes and suggests a human ancestral pericentric inversion which not only caused division of the two clusters but also caused reversal of the arm ratio.

Linkage analysis in a family with $X$ linked anophthalmos C A GRAHAM*, B G McClEARY*, S MALCOLM $\dagger$, E D KELlY*, A J HILL*, W P JOHNSTON*, AND N C NEVIN*

*Department of Medical Genetics, Queen's University, Belfast City Hospital, Belfast; and tMothercare Unit of Paediatric Genetics, Institute of Child Health, London.

$\mathrm{X}$ linked recessive anophthalmos is a rare eye disorder in which the affected males are born without eyes or with small non-functional eyes (microphthalmia). A family has been identified in Northern Ireland with a suitable structure for linkage analysis with DNA probes in order to map the location of this disease on the $\mathrm{X}$ chromosome. Results to date show that it is not localised on the short arm, as linkage was not found with $\mathrm{Xg}$ blood group or DNA probes pERT $87-15, \mathrm{XJ} 1 \cdot 1,754$, or $\mathrm{L} 1 \cdot 28$. However, probe DX13 showed only one crossover event $(10 \%$ recombination, max lod score 1.51 at $\theta=0 \cdot 1$ ) suggesting that the disease locus is localised towards the distal long arm. Linkage analysis with other probes in this region is continuing.

Interstitial deletion of the long arm of chromosome 2 with normal levels of isocitrate dehydrogenase

I A GLASS, C A SWINDLEHURST, D A AITKEN, W McCREA, AND E BOYD

Duncan Guthrie Institute of Medical Genetics, Yorkhill, Glasgow.

The most frequent interstitial deletions of the long arm of chromosome 2 involve the segments $\operatorname{del}(2)(q 31 q 33)$. We report a 16 year old boy who has mental retardation, microcephaly, epilepsy, craniofacial dysmorphism, and distinctive scalloped skin pigmentation. A $G$ banded karyotype of peripheral lymphocytes showed an interstitial deletion of the long arm of chromosome 2 giving a karyotype 46,XY,del $(2)(\mathrm{q} 32 \cdot 2 \mathrm{q} 33 \cdot 1)$. Identical karyotypes were found in fibroblasts derived from the normal and pigmented skin. Assay of the activity of isocitrate dehydrogenase in red cells gave normal activity for the proband, suggesting that the deletion breakpoint lies proximal to the structural gene for isocitrate dehydrogenase which previously has been mapped to $2 \mathrm{q} 33.3$ by somatic cell hybridisation and gene dosage studies. The breakpoints for this interstitial deletion have not been reported previously. An emerging phenotype for this subgroup, $\operatorname{del}(2)(\mathrm{q} 31 \mathrm{q} 33)$, of $2 \mathrm{q}$ deletions is confirmed by comparison of the proband with the other reported cases, but in addition this patient shows a distinctive pattern of skin pigmentation.

Pallister-Killian syndrome: emphasis of the phenotype in an adult

OLIVER W J QUARRELL, MERRYL A HAMILL, AND HELEN E HUGHES

Institute of Medical Genetics, University Hospital of Wales, Cardiff.

In 1977, Pallister et al (Birth Defects 1977;13:103-10) reported two adult patients and mentioned a third with coarse facies, profound mental retardation, and epilepsy. Cytogenetic studies of peripheral lymphocytes were normal but aneuploid cells owing to an additional isochromosome $12 \mathrm{p}$ were found in cultured fibroblasts. Subsequently, Teschler-Nicola and Killian (Synd Ident $1981 ; 7: 6-7)$ reported a three year old girl with abnormalities which are now recognised as typical of the Pallister-Killian mosaic syndrome. Since then the phenotype in children has been well documented and Pallister's original descriptions extended. We report a 36 year old man with mental retardation and very coarse facies who developed epileptic fits at the age of 22 years. He had a 
large tongue, thick lips, and prognathism. The head circumference was on the 90th centile; he had a high forehead and broad nasal root. Fibroblasts cultured from two skin biopsies showed no consistent abnormality but $13 \%$ of the cells examined from a third biopsy, which was not subcultured, contained an additional isochromosome 12p. Recognition of the phenotype in an adult was a prerequisite to directing the cytogenetic studies.

\begin{abstract}
Molecular analysis of a haemophilia $B$ mutation causing complete loss of factor IX activity

T C TSANG*, D R BENTLEY*, R S MIBASHAN $\dagger$, AND F GIANNELLI* ${ }^{*}$ Paediatric Research Unit, UMDS; and Haemophilia Centre, $\mathrm{KCH}$, London.
\end{abstract}

We have cloned the factor IX gene of a cross reacting material positive haemophilia $B$ patient with $<1 \%$ clotting activity and normal factor IX antigen level in the lambda vector, EMBL3. Overlapping recombinant clones encompassing the whole factor IX gene were isolated and the eight exons of the gene were subcloned in plasmid and M13 vectors for DNA sequence analysis. The only sequence deviation in the coding region is a CGA to CAA change in the codon specifying arginine at position 333 in the catalytic domain of the mature protein. The point mutation was confirmed by direct sequencing of in vitro amplified genomic DNA. The change to a glutamine residue causes the loss of a positive charge from the surface of the molecule. The mutation appears to pinpoint a previously unknown but functionally critical conserved feature of the protein, possibly involved in substrate or cofactor binding.

Deletion by illegitimate recombination of the factor IX gene in two relatives with haemophilia $B$ complicated by antibodies against factor $I X$

P M GREEN*, D R BENTLEY*, $R$ S MIBASHAN $\dagger$, AND $F$ GIANNELLI*

*Paediatric Research Unit, UMDS; and †Blood Coagulation Unit, KCH, London.

Deletion of the factor IX gene predisposes haemophilia B patients to develop antibodies to administered factor IX. We have analysed the factor IX gene deletion of two related patients with such a complication. The deletion removes $23 \mathrm{~kb}$ of DNA comprising the last three exons coding for the activation peptide and catalytic domain and $10.3 \mathrm{~kb}$ distal to the last exon. The $5^{\prime}$ break is $704 \mathrm{bp} 3^{\prime}$ of exon $e$ at residue -113 of an Alu repeat. No significant homology exists between the $5^{\prime}$ and $3^{\prime}$ termini. At the cloned junction a new 16 bp sequence contributes a DraI site also found in the genomic DNA of the two patients and a heterozygous relative. It is proposed that deletions by illegitimate recombination such as that described above occur principally during DNA replication. Presumably the loss of $3^{\prime}$ sequences involved in the maturation of mRNA results in no factor IX production in the patients and their antibodies are directed towards epitopes coded by both the $\stackrel{\overparen{D}}{?}$ deleted and non-deleted segment of the gene.

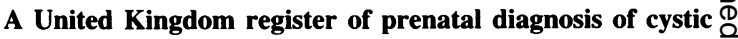
fibrosis using linked DNA probes

MAURICE SUPER AND CHRISTINE BAILEY

Paediatric Genetics, Royal Manchester Children's Hospital, $\vec{\circ}$ Manchester.

Since mid-1986 a register of all prenatal diagnoses of cystic fibrosis by linked DNA probes has been kept in the United Kingdom. All centres known to be involved in this work contribute and complete detailed questionnaires. A total of 194 prenatal diagnoses had been reported by February 0 1988. There had been 22 terminations of pregnancy and $\mathscr{\omega}$ the births of 31 children had been reported, all free of CF, $\infty$ as predicted. In the remainder the pregnancy was either $\mathrm{O}$ continuing or the birth had not yet been reported. There appear to be local differences in efficiency of chorionic $\circlearrowleft$ biopsy. With present inability to confirm a diagnosis of CF in the aborted fetus, a very important aspect of this register $\overrightarrow{\mathbb{D}}$ is country-wide reporting on validation of the accuracy, when freedom from CF has been predicted. The support of $\mathbb{D}$ the Cystic Fibrosis Research Trust and of colleagues who $\vec{\oplus}$ provide information is gratefully acknowledged.

Non-radioactive in situ hybridisation: comparisons methodology

D H SPATHAS, S S M HABEEBU, AND M A FERGUSON-SMITH Department of Pathology, University of Cambridge, Cambridge.

We have used GMGY10, a moderate repeat probe on Yp, to compare the speed and resolution of non-radioactive in situ hybridisation methods with human chromosomes and $\overline{3}$ nuclei. Biotinylated probes were detected by the streptavidin/alkaline phosphatase/NBT reaction (SA-AP) under phase contrast microscopy (Garson et al, Nucleic Acids Res 15:4761), peroxidase/DAB reaction (PO/DAB), 을 under reflection contrast microscopy (RCM) (Landegent et al, J Histochem Cytochem 33:1241), and with FITC 윽 conjugated antibodies (Cremer et al, Hum Genet 74:346). I Mercurated probes were similarly detected by PO/DAB (Hopman et al, Nucleic Acids Res 14:6471) and FITC fluorescence (Wachtler et al, Exp Cell Res 167:227). We N have found that the biotinylated approach with any of the $\mathrm{N}$ detection systems we have used gives a very high propor- 0 tion of positive metaphases and nuclei. In particular, $\omega$ detection by $\mathrm{PO} / \mathrm{DAB}$ with RCM gives the best resolution with a distinct hybridisation spot on each chromatid. It is 0 also the most efficient method in terms of speed, simplicity, $\frac{\bar{\Phi}}{\mathbb{D}}$ and signal to noise ratio. Chromosome morphology is in general better preserved with the biotinylated approach. $\tau$ Work is in progress on the further comparative evaluation of these methods for detection of single copy sequences and use in clinical studies. 
Molecular analysis of chromosome 11 in Wilms' tumour from a child with chromosome breakage syndrome ANNE SEAWRIGHT*, J R W YATES $\dagger$, R CARACHI $\ddagger$, AND V VAN HEYNINGEN*

${ }^{*}$ MRC Clinical \& Population Cytogenetics Unit, Edinburgh; †Medical Genetics, and $\ddagger$ Royal Hospital for Sick Children, Glasgow.

Normal tissue DNA (from fibroblasts and an EBVlymphoblastoid line) of this child was shown to be heterozygous for polymorphic alleles at six loci along chromosome 11p13-pter. Analysis of parental DNA for some of these markers confirmed their correct Mendelian inheritance. Examination of tumour DNA showed a loss of heterozygosity for a marker proximal to the WAGR region. Quantitative dosage analysis for this latter marker and one of the distal ones at which heterozygosity was lost suggests that allele loss in this case has arisen by loss of part of one chromosome 11 homologue rather than by the more usual mitotic recombination mechanism seen in Wilms' tumour (Dao et al. Am J Hum Genet 1987;41:202-17).

\section{Cytogenetic investigations in a family with ataxia telangiec-} tasia

M W HUMPHRIES*, N C NEVIN*, AND M A W WOOLRIDGE $\dagger$

${ }^{*}$ Regional Cytogenetic Laboratory, Department of Medical Genetics, Belfast City Hospital, Belfast; and †Altnagelvin Hospital, Londonderry.

Cytogenetic studies were carried out in a family with ataxia telangiectasia (AT) in which three of four sibs were affected. Spontaneous chromosome breakage and G2 chromosomal radiosensitivity were investigated in each affected subject, the parents, a normal sib, and a normal control. Affected subjects were found to have twice the level of spontaneous chromosomal aberrations when compared to the control. The parents and normal sib showed no significant increase in the level of spontaneous aberrations. With $\mathrm{G}$ banded preparations, several cells from the three AT homozygotes had chromosomal rearrangements, which non-randomly involved chromosomes 7 and 14 . Within the rearrangements, the breakpoints were located within four sites, $7 \mathrm{p} 14,7 \mathrm{q} 35,14 \mathrm{q} 12$, and $14 \mathrm{q} 32$. No chromosomal rearrangements were encountered in the control, parents, or normal sib. Lymphocytes from the AT homozygotes also were found to be between seven to 10 times more sensitive to the induction of chromatid type aberrations by $\mathrm{X}$ radiation than lymphocytes from the control. Interestingly, lymphocytes from the parents and normal sib were found to have a frequency of $\mathrm{X}$ radiation induced aberrations approximately twice that found in the control.

\section{A study of 33 families who have at least one child affected with cystic fibrosis \\ BARBARA GIBBONS, JOSEPHINE AFFLECK, P FARNDON, AND P WELLER \\ Clinical Genetics Unit, Birmingham Maternity Hospital, and Birmingham Children's Hospital.}

We visited an unselected group of 33 families with at least one child with cystic fibrosis ascertained through the West Midlands Neonatal Screening Survey to determine: (1) family structure, (2) method of diagnosis and present health, (3) knowledge of the disease process, (4) knowledge of the genetics of CF, (5) family planning, (6) knowledge of prenatal diagnosis, (7) acceptability of prenatal diagnosis. Families then received a fact sheet outlining the mode of inheritance of CF and the prenatal diagnostic tests available. In our study only $45 \%$ of the families felt that prenatal diagnosis was acceptable, unlike those families who ask to attend the genetic clinic, and $33 \%$ of the families in the study did not agree with termination of pregnancy in principle. It appears that, as at present the health of most of the children is good, some parents find it difficult to accept prenatal diagnosis and termination of pregnancy as a option in future pregnancies.

cDNA deletions in Becker muscular dystrophy

SARAH ENGLAND, DONALD LOVE, SUSAN FORREST, AND KAY DAVIES

Nuffield Department of Clinical Medicine, Oxford.

We have previously shown that $50 \%$ of BMD patients are deleted in exactly the same manner in the central region of the dystrophin gene. One of these patients shows an altered restriction fragment enabling the cloning of this deletion 'hotspot'. Two very mild BMD patients are deleted for $5 \mathrm{~kb}$ or more of the $14 \mathrm{~kb}$ cDNA. This suggests a compensating mechanism for the absence of dystrophin in their muscle cells or the function, albeit impaired, of a considerably truncated protein molecule.

Linkage analysis in neurofibromatosis type 1 (NFI)

C G P MATHEW*, K THORPE* ${ }^{*}$ c WALLIS $\dagger$, C SLATER $\dagger$, AND B A J PONDER*

*Institute of Cancer Research, Surrey; and †University of Cape Town, South Africa.

Linkage analysis of 20 British and South African Indian families with NF1 was undertaken using eight probes from the pericentromeric region of chromosome 17. Several probes were linked at a low recombination frequency. Crossovers in families informative with several markers showed that the NF1 gene is located proximal to EW204 and EW207 close to the centromere. Linkage of NF1 to these markers was also detected in the Indian families, in spite of their atypical phenotype. (We thank D Barker and $R$ White of the University of Utah for providing the chromosome 17 probes.)

Specific methylation at the hypervariable $D X S 255$ locus on active $X$ chromosomes: a simple system for the assessment of $X$ inactivation status

Y BOYD*, N J FRASER $\dagger$, AND I W CRAIG $\dagger$

*Genetics Division, MRC Radiobiology Unit, Chilton, Didcot; and tGenetics Laboratory, Department of Biochemistry, Oxford.

Previous characterisation of an $\mathrm{X}$ chromosomal sequence mapping to Xcen-Xp11.4, M27 $\beta$ (DXS255), showed that it 
detected $95 \%$ heterozygosity in females (Nucleic Acids Res $1987 ; 15: 9616)$. We have investigated the potential use of this probe to differentiate between active and inactive $\mathrm{X}$ chromosomes through the methylation patterns revealed by the restriction enzyme MspI (recognition site CCGG) and its methylation sensitive isoschizomer HpaII. Experiments were carried out using DNA prepared from blood and from cell lines with defined patterns of $X$ inactivation. Preliminary results suggest that the CCGG sites flanking the $D X S 255$ locus are extensively methylated on active X chromosomes and unmethylated on inactive $\mathrm{X}$ chromosomes. The high degree of heterozygosity detected, combined with this differential methylation pattern, indicate that this simple system should be applicable to many situations where assessment of $\mathrm{X}$ inactivation status is required (for example, imprinting, females with $\mathrm{X}$ linked disorders, analysis of clonal development in tumours).

Reduced activity of enzymes bound to the microvillar membrane fraction of amniotic fluid from pregnancies with cystic fibrosis

D A AITKEN, J A H MAATOUK, G W GRAHAM, E GRACEY, AND J M CONNOR

Duncan Guthrie Institute of Medical Genetics, Yorkhill, Glasgow.

Amniotic fluid (AF) microvillar enzyme activity is known to be reduced in second trimester pregnancies where the fetus has cystic fibrosis (CF). An alternative approach to assaying the soluble component of these enzymes is to isolate the fragments of microvilli present in the $\mathrm{AF}$ supernatant for direct analysis (Potier et al, Prenat Diagn $1986 ; 6: 429-36)$. We report here the results of a preliminary investigation of the enzyme activity associated with the microvillar membrane fraction of AF supernatant from three pregnancies in which the fetus was terminated with
$\mathrm{CF}$, and in a series of normal controls. The yield of $\stackrel{\mathbb{T}}{+}$ microvilli from the CF samples was found to be in the same $\vec{\Rightarrow}$ range as that from the control group, but the specific? activities of the microvillar enzymes maltase, gammaglutamyltranspeptidase, and intestinal alkaline phosphatase were significantly lower $(p<0 \cdot 001)$ in the microvilli pre- $\frac{\bar{p}}{-}$ parations from the CF cases. These results suggest that $\propto$ enzyme analysis of purified microvillar membrane fragments may be a more discriminating test for the prenatalos diagnosis of $\mathrm{CF}$ than assay of these enzymes in $\mathrm{AF}_{\overrightarrow{0}}$ supernatant.

Wide spectrum of symptoms in Stickler's syndrome M TOLAROVÁ J ŠPINDRICH, L BAŘIINKA, AND J SAMOHÝL Institute of Experimental Medicine, Lid milici 61,12000 $\mathrm{N}$ Prague 2, Czechoslovakia.

Stickler's syndrome (hereditary progressive arthro- ${ }^{\infty}$ ophthalmopathy) is a serious autosomal dominant condi- $\frac{}{5}$ tion, which is increasingly diagnosed in genetic counselling $\vec{C}$ clinics. Owing to variation in severity and expressivity, this $\mathbb{D}$ condition often presents diagnostic problems. The main features are progressive myopia and choroidoretinal $\frac{\mathbb{\Phi}}{3}$ abnormalities in childhood, sometimes leading to retinalo detachment or glaucoma, and Robin anomalad and en- $\stackrel{\mathbb{D}}{-}$ largement of large joints, particularly of the wrist, knees $\vec{\bullet}$ and ankles, which may be present at birth. In middle age, repeated episodes of acute arthritis may occur and precese degenerative arthropathy, considerably impairing te physical activity of the patient. Inconsistent featuress include conductive deafness, cleft palate, structural abnor- $\frac{\partial}{\partial}$ malities of the vertebrae, and mental retardation. Ten families with 16 cases have been examined and clinical $\stackrel{\circ}{\mathcal{Q}}$ symptoms, dysmorphological features, and radiology, characteristic for different ages, are pointed out.

\section{Correction}

In the abstracts of the November 1987 meeting of the Clinical Genetics Society ( $J$ Med Genet 1988;25: 274-83), an error occurred in the abstract by Redha et al on page 278. The penultimate sentence? should have read "In the $45, X$ cases loss of the paternal homologue was observed in all cases". 